\title{
INNOVATION IN AIRPORT DESIGN
}

\author{
Alexander MEDVEDEV ${ }^{1}$, Iyad ALOMAR ${ }^{2}$, Slawomir AUGUSTYN ${ }^{3}$ \\ 1, 2 Transport and Telecommunication Institute, Lomonosova 1, Riga, LV-1019, Latvia \\ ${ }^{3}$ National Defence University, Gen. A. Chruściela 103, 00-910 Warsaw, Poland \\ E-mails: ${ }^{1}$ medvedevs.a@tsi.lv; ${ }^{2}$ alomar.i@tsi.lv (corresponding author); ${ }^{3}$ s.augustyn@aon.edu.pl
}

Received 07 July 2016; accepted 03 March 2017

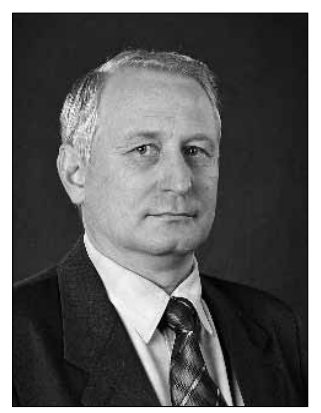

Alexander MEDVEDEV, Prof., Dr. Sc. Eng.

Fields of research: transport and logistics.

Present position: Professor; Head of the Chair of Aviation transport; member of the TTI

Research committee; member of the Latvian operation research society; member of the Latvian association of professors at institutions of higher education; manager of theoretical training and examination of the EASA Part-147 training Centre at TTI Academic and professional aviation centre TSI/APAC.

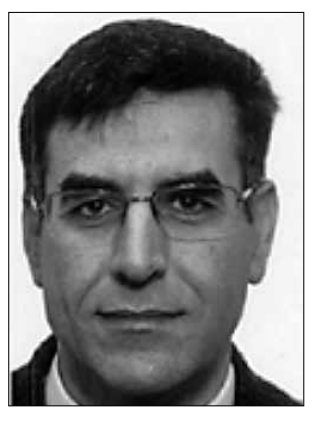

Iyad ALOMAR, MSc in engineering

Fields of research: transport and logistics.

Present position: lector; Type training manager and Deputy of Quality manager of the EASA Part-147 training Centre at TSI/APAC (TTI Academic and professional aviation centre).

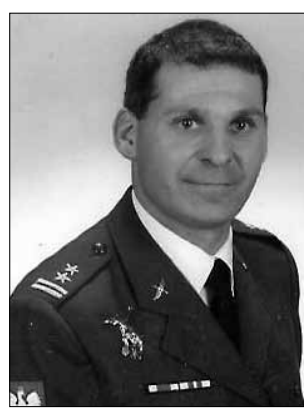

Slawomir AUGUSTYN, Assistant Professor.

Fields of research: transport and logistics.

Present position: Assistant Professor at the National Defence University (Warsaw, Poland).

Abstract. This article discusses the issue of innovation in airport design which is supported by aviation project management. This is why the decision making process on innovation in an airport's design should correlate with future perspectives in aviation. This process influences a decrease in time and money lost during the period of leading an aviation project. A good result is obtained through selected essential information and analysis of the airport management process in order to achieve efficiency in aircraft operation. What is more, the innovation in airport design is closely related with the safety of aircraft and security of passengers.

Keywords: aircraft operations, ground handling, aviation project management, innovation, airport design. 


\section{Introduction}

The innovation in airport design is targeted at service providers in aviation. The service providers in aviation usually focus not only on the quality of the service, but also on the efficiency of aircraft operation. The innovation in airports design is complex future thinking about a high degree of competition while using new methods of vehicles movements controls at the aerodrome and aviation equipment developments by new methods, tools, materials with sustainable technologies and good airport organized infrastructure, etc It is very important, because all these components are necessary for effective air operations and also effective ground handling in the context of passenger's security.

Due to a huge demand in expanding airport capacity caused by the increasing amount of passengers and good flows, air travel has become accessible to billions more travellers. In 2012, 2.8 billion passengers used air travel. According to IATA's 2050 report, experts expect that 16 billion passengers and 400 million tons of cargo will be used by aviation transport in 2050 and will continue to increase (IATA 2011). It is a huge challenge to provide this incensement without a good organization of the operation circuit involved in aircraft operations, including the time when the aircraft stands on the ground.

Many studies have been carried out in order to tackle the growing passenger flows. Bonnefoy et al. (2010), issued a study known as "Evolution and Development of Multi-Airport Systems". The core of their solution was creating Multi-Airport Systems. A multi-airport system is defined as a set of two or more significant airports that serve commercial traffic within a metropolitan region. However, with this solution they determined that the congestion problem at the three major airports in New York could also drive the emergence of a new secondary airport. Nevertheless, the development of a multi-airport system still poses several challenges in terms of planning and development Bonnefoy et al. (2010).

From point of view De Neufville, Professor of Engineering Systems and Civil and Environmental Engineering Massachusetts Institute of Technology, also issued a study in this area in his article "Airports of the Future: The Development of Airport Systems". In another study, the worldwide development is presented in terms of emerging trends towards focused specialization in airport operations; the major types of airports are defined (de Neufville 2003):

a) $24 / 7$ intercontinental airports serving the global international passenger traffic;

b) cheap fare, short haul airports that strive to be inexpensive to match the demands of their clients;

c) cargo airports dedicated to serving integrated freight operators.
In an article by Price and Dreiling the proposed future aerotropolis airport model allows argueing that airports act as cities: home to people, businesses, industries, and are a pivoting point for economic growth. A cultural and organizational transformation within the airport sector supported by business model innovations will be required to accompany such a monumental shift towards the future operations of airports (Price, Dreiling 2013).

Design led innovation requires a company to have a vision for top line growth, which is based on deep customer insights and expanded through customer and stakeholder engagements. The outcome of design led innovation is the integration of design and a culture of design thinking within all aspects of a business to enable that vision to be achieved.

Innovations in digital technology hold the ability to support the operation of the physical environment of an airport whilst creating new and potentially disruptive channels to customers and stakeholders. The rise of the digital economy presents an interesting link to the future aerotropolis business model of airport operation.

The smart follower or innovation-adopting organization selects and absorbs the success of innovation generators and leaders within and outside of their industry, reducing the risk of market failure. However, this approach toward innovation also cements the risk and innovation adverse cultural dynamics within stakeholders, which can yield low organizational creativity and deficiencies in problem solving.

As stated in the laws and regulations on aerodromes, there are five main factors which play a major role in improving airport capacity (Abeyratne 2014):

d) integration of GNSS use;

e) integration of arrival/departure/surface management;

f) optimization management;

g) improvement of surface surveillance;

h) airport collaborative decision making.

It is impossible to improve items (b) and (d) without the good management and optimization of the movement and operation of ground vehicles.

On the other hand, the number of accidents and incidents which take place at aerodromes due to ground vehicle operations, and the impact of aircraft by these vehicles are rapidly increasing.

In the Transportation Research Board (2008) we saw that one of the major goals of this research project was not only to identify innovations, but also to understand and evaluate their potential effects on airport terminal landside facility planning and design. As a result, several new landside and terminal concepts that incorporate one or more innovations have been developed.

The landside concepts are based on the passenger processes described earlier and include activities from 
the beginning of the passenger's journey to the point where the passenger enters the terminal building, and vice versa.

ICAO and EUROCONTROL have devised the "Advanced-Surface Movement Guidance and Control System" (A-SMGCS) to ensure the safety and the efficiency of surface traffic on the airport movement area (runways, taxiways and apron area) (Eurocontrol 2015).

The most extensive studies were provided by a Portuguese team of scientists (Casaca et al. 2015). They explain that the present level of technological development in information and communication technologies allows defining a low cost platform for the vehicle navigation component of the A-SMGCS, and gives a good presentation and ideas on how to use and integrate widely known communication network systems, such as: $\mathrm{Wi}-\mathrm{Fi}$, TETRA, CDMA and WiMAX, to optimize the ground vehicle movement within a local area airport network.

Azorín Gonzalez et al. stated that the optimization of future ground operations of aircraft cannot be understood without studying the main platforms. For this purpose two projects stand out - Next Gen. and SECAR (Azorín Gonzalez et al. 2013).

The Next Gen. Air Transportation System (Next Gen) aims to transfer America's air traffic control system from the current ground based system to a satellite based system with a GPS technology feature. They assume that when dealing with airport operations, some points override others. These points were grouped in the following way:

i) A-CDM (Airport Collaborative Decision Making);

j) unambiguous communications;

k) runway entrance control;

l) no confusing lights - less stop and go;

m) continuous taxi speed - improved controller efficiency;

n) optimizing the use of available infrastructure;

o) A-SMGCS (Advance Surface Movement Guidance and Control Systems).

This study only dealt with aircraft departure and runway occupation and holding time. They looked at the optimization only from the aircraft's point of view, regardless of other conditions surrounding it.

Around $90 \%$ of airports' infrastructures using a ground handling system and with good management of it can be regarded as having a good aviation project management. That is why the innovation in airport design should give a realistic overview of a typical service provider involved in airlines, airports, as well as in high quality and safety manufacturing operations. Also, it is obvious that the innovations in airport design should create the interdependence between the safety of aircraft operations and the satisfaction of passengers in terms of economical aspects. The most important airport features are time, safety, security and the amount of money spent, so the passengers are interested in technologically advanced projects. All customers look for a high level of comfort and satisfaction. However, all those things cannot be provided without proper management organization and good organization of the grand holding. Of course the cost value should be the most important criterium in the quality of handling service, because the total quality of service is the single and the most important issue in providing a passenger service successfully. That is why the innovation in airport design should take into consideration the following aspects:

1. First the future project should be dealing in parallel with two areas:

- air navigation system;

- airport infrastructure.

2. The usage of new technology in ground handling for almost two decades has centred on ground transport interchange.

3. Human errors in all aspects should be reduced in the aviation market. Obviously, the high service quality leads to customers' retention, which has shown to be cheaper in the long term, with high levels of customer turnover.

\section{Design of future airports}

Innovation in airport design has a crucial role in the aviation safety chain, linking airline safety with their passenger security and customer freight. They are centres of economic activity that attract business parks and serve as multi-modal transfer points. It is a complex of newdesign airport buildings and security infrastructure systems that serve the needs of a variety of interests from time to time. Most of these interests are concentrated in the new-construction terminal building (airline park with their aircraft for loading and unloading, passengers' baggage and their transportation between ground transport and aircraft). Airlines, the airport operator, and businesses want to provide continuous services and assist passengers and airport visitors, and the terminal building supports these activities. Future concepts of modern airports address three basic elements:

- more comfortable handling of passengers;

- capacity and quality increase with a high level of air operations;

- reduction of the environmental impact on nature using clean energy projects, for example to reduce $\mathrm{CO}_{2}$.

Larger airports have grown, and this has provided the knowledge on how to predict and solve the major problems, such as optimal use of the airport capacity, insufficient runway capacity, etc.

Nowadays, terminal buildings are renovated, upgraded and modified. In addition, entertainment places 
were built to accommodate the growth in air travel. In the future, most of the existing airports will be renovated taking into account the comfort of facilities, where the terminal building must be rebuilt within the constraints of the existing property, runway, boundaries and highway systems regarding the safety of continuing airline operations. It is improbable that the future terminal buildings will be radically different in the basic concept, but surely they will be larger and busier than any airports that currently exist.

The traditional structure of an aviation project management is characterized through routine work process and planning, organizing, controlling and coordination process, within the structure of line organization. In order to achieve the proper capacity and quality, the innovation in airport design should be assessed to avoid problems with legislation. One of the ways to achieve success in designing an airport is the choice of a suitable method in aviation project management. The survey of new areas of investigative co-operation in different scientific disciplines is required. The necessary strategies of using modern technologies for safety and security are one of the most important research areas. Integrating technical, environmental, psychological and economical sciences (Fig. 1) creates the chances of a better result in airport design.

Moreover, airports' design should be based not only on the supervision of procedures, the power of aviation project management, and the formal security rules to obey, but also on passengers' rights. Despite this, the project tools for airport design are well known and available, e.g. risk analyzes, planning, organizing, doing, controlling and budgeting. Aviation projects could fail. This is not due to lack of methods and techniques, but sometimes due to poor correlation between the innovation power of doing aviation projects and the human resource management dealing with natural environment protection.

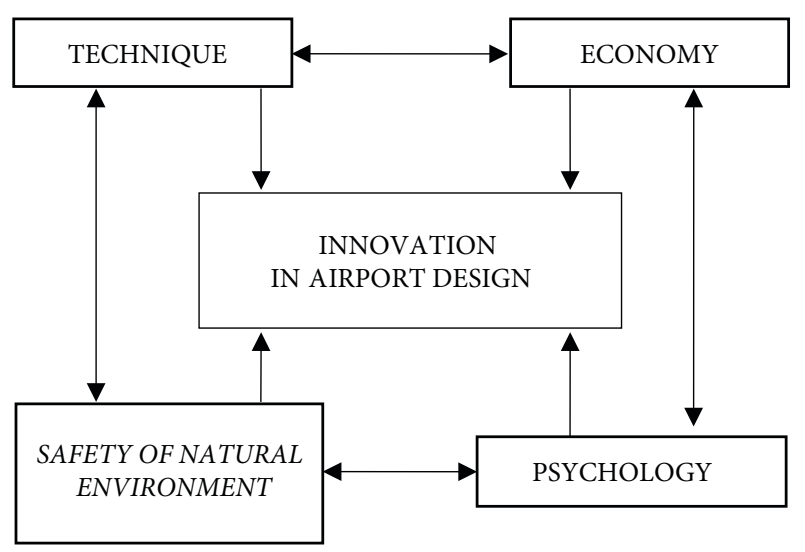

Fig. 1. Integration of different scientific disciplines for innovation in airport design (Augustyn 2010)
What is more, the relation between the awareness of employees (team) and environmental protection can improve the level of quality of airport project management.

The new approach to innovation in airport design shows a wide and novel vision of work organization with regard to natural environment protection that encompasses:

- innovative technology combined with a new project process for leading an aviation project;

- an improvement in acknowledging working teams in an airport project;

- a new solution to essential problems to achieve success in the airport structure;

- education improvement of the aviation project team.

This concept provides guidelines for leading an aviation project so as to decrease the cost level and improve the level of aircraft safety and natural environment protection.

\section{The perspective to airport design}

The perspective to airport design presents a new way of approaching the culture, structure and communication procedures of the team workers (Fig. 2). The methodology should be based on the following aspects:

1. Defining the problem or challenge and mission of the airport project.

2. Logical structuring of the airport project regarding the interim results and specific activities.

3. Correlating the decision-making process when developing the airport project with natural environment protection.

Planning and controlling the timeline, money, quality, information and communication in the organization of the airport project.

That is why the good airport design could give a perspective systematic way of developing of the process.

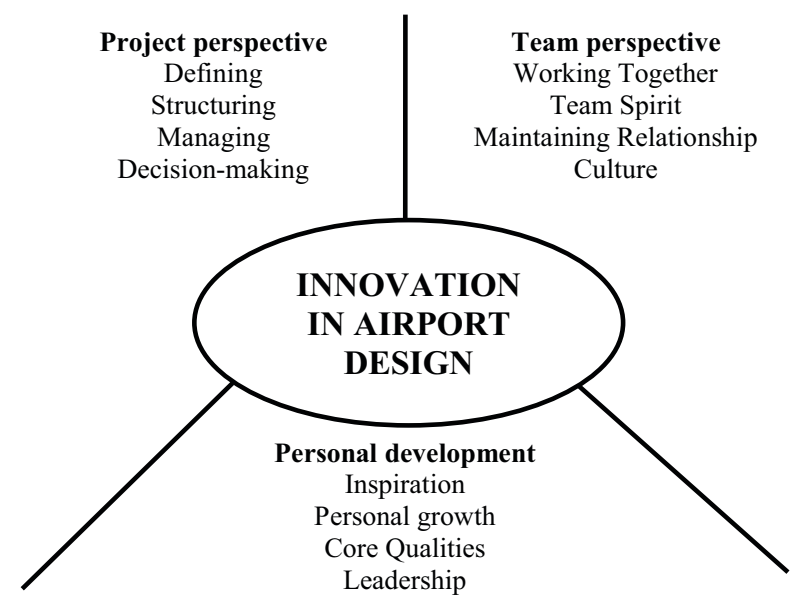

Fig. 2. The new perspective to airport design (Ofman 2001) 
The innovation in airport design could be created on a minimum of two or more pillars. The two pillars give support to leading an airport project based on:

- finding and making the optimum use of the power of imagination, the power of co-operation and the power to shape structure;

- synergy of viewing leadership as a personal development perspective to obtain a good result of the project team work and the success from an aviation product perspective.

Additionally the innovation in airport design should correlate with three perspectives and three powers for the enterprise.

1. The personal development perspective is supported by the power of Imagination.

2. The project team's perspective and the power of Co-operation, the target being team synergy, mutual trust and good management of relationships in and around the aviation project.

3. The project perspective, supported by the power to Shape, ensures the management of time, money, quality and other control factors.

Aviation projects are very often successful when the investor, project team and line managers choose to face the challenge together. This provides involvement, positive energy, satisfaction and a good desired result.

The following elements are provided as an example based on a good aviation project targeted at successfully defining passenger IDs:

- the airport project mission;

- the airport project challenge and problem of definition;

- the desired airport project result;

- the demarcation of the aviation project result;

- the airport project effects;

- the impetus of the airport project;

- the preconditions under which the airport project is enacted.
When the airport project definition is clear, the project team is able to carry out activities in the structure of project.

Moreover, instead of following a strictly logical linear approach, the project team should use a creative structuring process. The desired result of any aviation project is a control factors during the project set up: timeline, money, quality, organization, communication and environmental law (Fig. 3). These control factors influence the project's result as a quality product. Together, the control factors allow:

- for an effective project team (organization) within a certain period (timeline);

- making use of budget (money);

- using data (information), culture, passenger rights;

- remaining in close contact (communication) with the natural environment.

In other words, the new perspective to aviation project management proposes a process for obtaining a high quality level of an aviation product.

Without innovative data collection methods, it is impossible to include any innovation in airport design that would match with a new secure and progressive aviation market.

New technologies give us a wide selection of choices of data collection units, such as:

a) positioning system sensors, like GPS sensors and a peeling system.

b) video information. Using special intelligent programs which transfer video images into an event log. For example from a video image the program can set a protocol about trolley No. 20 reach point $\mathrm{x}$ at time $21 \mathrm{~h} 34 \mathrm{~m} 12 \mathrm{~s}$. This program may something like the Real-time Transport Protocol (RTP). (Schulzrinne et al. 2003).

c) information interpretation from various elements of the system that uses various sensors installed in the system elements.

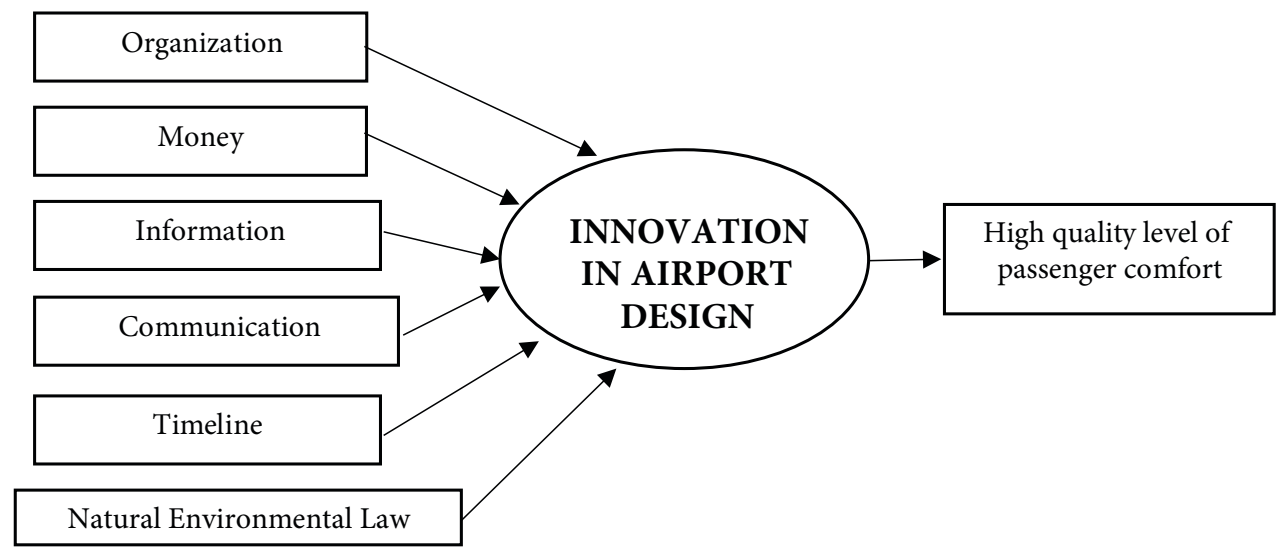

Fig. 3. The transformation process in aviation project management (Augustyn 2011) 
d) a person who is involved in providing information about the state of each system element via communication devices.

All these 5 methods can provide new information data streams required for the simulation and modelling of the whole process, including the movement of the aircraft itself.

It is notable that although for our study the coordinates $(x, y, z)$ of each separate system element are important; the state of these elements also has a very high degree of importance.

The above described system can be useful in aviation, because it can:

a) improve the safe movement of vehicles in the aerodrome, since the whole process will be automated and under real-time control;

b) increase the productivity of the system (logistics index), as a result of minimizing the time lost during aircraft servicing. Also this system can be linked to the ATC system, and, in case of any delay or change in aircraft schedule, the whole system on the ground will be able to react in time and reset itself in order to match the new slot time;

c) decrease the carbon emissions in the atmosphere, since all vehicles can be controlled from a control centre, and the control centre can choose the shortest way and the starting point from which the vehicles will start moving, depending on an aircraft's stand.

\section{Conclusions}

The innovation in airport design combined with environmental protection is the transformation process for the project being designed. In practice this way is not very simple and each project team should understand what should be done in such an airport project.

The managers should find an inspiring concept for creating the airport project. This new concept of airport design goes against traditional ideas about organization, communication and the spirit of thinking in co-operation with people who work in environment protection.

In summary, we can argue that the new concept to airport design in all selected aviation segments is based on a network of highly interdependent external and internal customer-supplier relationships. Many service providers do not directly serve their end customers but rather serve another service provider who does. In order for them to optimize and generally improve their service quality is justifying.

\section{References}

Abeyratne, R. 2014. Low and regulation of aerodrome. Springer International Publishing. https://doi.org/10.1007/978-3-319-04780-5

Augustyn, S. 2010. The new approach to aviation project management. AON, Warsaw.

Augustyn, S. 2011. Human factors in aviation safety investigations. Acta Avionica, Kosice.

Azorín Gonzalez, I.; Burgaz Aranguren, B.; de Diego Parra, S.; Rodriguez Martínez, J.; Galán Olea, M.; Nakhaee-Zadeh Gutierrez, A. 2013. Optimization of future ground operations for aircraft. Universidad Rey Juan Carlos.

Bonnefoy, P. A.; de Neufville, R.; LM ASCE; Hansman, R. J. 2010. Evolution and development of multi-airport systems. A worldwide perspective, Journal of Transportation Engineering 136(11): 1021-1029. https://doi.org/10.1061/ (ASCE)0733-947X(2010)136:11(1021)

Casaca, A.; Pestana, G.; Rebelo, I.; Silva, T. 2015. A platform to increase the safety of ground movements in the airside area of airports [online], [cited August 2015]. Available from Internet: https://www.ana.pt/SiteCollectionDocuments/ Sobre\%20a\%20ANA/ArtigosPublicados/20090000_APlatformIncreaseSafetyGround.pdf

de Neufville, R. 2003. Airports of the future: the development of airport systems, in International Symposium and Exposition in Celebration of 100 years of powered flight 14-17 July 2003, Dayton, Ohio.

Eurocontrol. 2015. Advanced-Surface Movement Guidance and Control System (A-SMGCS) [online], [cited August 2015]. Available from Internet: http://www.eurocontrol.int/articles/advanced-surface-movement-guidance-and-controlsystems-smgcs

International Air Transport Asociation (IATA). 2011. Vision 2050 report. Singapore, 12 February 2011.

Ofman, D. 2001. Inspiration and quality in organization. 11th ed. Utrecht: Service publications.

Price, R.; Wrigley, C.; Dreiling, A.; Bucolo, S. 2013. Design led innovation: shifting from smart follower to digital strategy leader in the Australian airport sector, in Proceedings IEEE Tsinghua International Design Management Symposium: Design-Driven Business Innovation, Institute of Electrical and Electronics Engineers, 1-2 December 2013, Shenzhen, China, 251-258.

https://doi.org/10.1109/tidms.2013.6981245

Schulzrinne, H.; Casner, S.; Frederick, R.; Jacobson, V. 2003. RTP: a transport protocol for real-time applications. Network Working Group, July.

Transportation Research Board. 2008. Innovations for Airport Terminal Facilities. Airport Cooperative Research Program. Report 10. Transportation Research Board, Washington, D.C. 